\title{
El proceso de escribura académica en estudiantes universitarios de primer año
}

\author{
Academic writing process in first year \\ university students
}

Laura Sáenz Dominguez ${ }^{1}$ https://doi.org/10.46954/librosfahusac. 7

\section{Resumen}

OBJETIVO: analizar la importancia que le dan los estudiantes al proceso de escritura académica y proporcionar estrategias que pueden orientar a los docentes en la tarea de enseñar a escribir. MÉTODO: el instrumento que se utiliza es la Encuesta Europea sobre la Escritura Académica (EEEA), en específico la dimensión de proceso de escritura, la cual consta de 13 ítems. Los sujetos encuestados son 183 estudiantes de primer año quienes expresaron qué tan importante es el proceso de escritura académica y sus características. RESULTADOS: de todo el proceso de composición existe menos énfasis en la planificación, y leer y evitar el plagio fueron los ítems que consideraron más importantes. CONCLUSIÓN: comprender la percepción que tienen los estudiantes respecto al proceso de composición permite tomar acciones que contribuyan a que gestionen estrategias de planificación, textualización y revisión durante su recorrido universitario.

Palabras clave: proceso de escritura, escritura académica, primer año, estudiantes, estrategias 


\section{Abstract}

OBJECTIVE: to analyze the importance that students give to the academic writing process and to provide strategies that can guide professors in the task of teaching writing. METHOD: the instrument used is the European Survey on Academic Writing (EUWRIT), specifically the writing process dimension, which consists of 13 items. The surveyed subjects are 183 first-year students who expressed how important is the academic writing process and its characteristics. RESULTS: of the entire composition process there is less emphasis on planning, and reading and avoiding plagiarism were the items that they considered most important. CONCLUSION: understanding the perception that students have regarding the composition process allows taking actions that contribute to managing planning, textualization and revision strategies during their university journey.

Keywords: writing process, academic writing, first year, students, strategies.

\section{Introducción}

El proceso de escritura académica constituye toda la constelación de actividades en torno a escribir. Se refiere a un conjunto de acciones que en coordinación permiten producir un resultado que cuenta con características propias. De esta manera, cada texto es una nueva oportunidad de aprender a escribir porque requiere que un individuo lleve a cabo una alta actividad cognitiva.

En el primer año de universidad los estudiantes utilizan tipos de textos con los que nunca han trabajado y el acompañamiento que reciban marcará su éxito estudiantil porque se exponen a nuevas situaciones de comunicación (Carlino, 2007). Por eso, las instituciones de educación superior buscan ayudarlos a mejorar el proceso de composición, pero para lograrlo es clave conocer la perspectiva estudiantil de cómo lo visualizan y la importancia que le dan a cada una de las etapas: la planificación, la redacción y la revisión. 
Para lograrlo, en el caso de la escritura académica, es necesario comprender cómo se desarrolla la escritura en contextos específicos. Esto para comenzar a conocer las acciones docentes que llevan a que los estudiantes vean el potencial de cultivar esta habilidad. Por eso, en este texto se presentan los resultados de una investigación donde se analiza la importancia que le dan los estudiantes tanto al proceso de escritura como a sus características y se discuten estrategias que pueden orientar a los docentes en la tarea de enseñar a escribir.

\section{Fundamentación teórica}

Este trabajo se enmarca dentro de la línea de investigación de la didáctica en la educación superior. Tovar y Samacá (2017) realizan un recorrido por la historia del concepto de la didáctica y concluyen que es una disciplina que forma parte de la pedagogía de la enseñanza-aprendizaje y debe evolucionar de acuerdo a cómo se desenvuelven los estudiantes de educación superior. En estos tiempos, con un mundo tan cambiante y cada vez más globalizado, también se debe tomar en cuenta que la clave es adaptarse a los cambios.

La investigación relacionada con la escritura ha evolucionado desde el estudio de los procesos cognitivos, a la inclusión del contexto y, finalmente, con la diferenciación de las culturas institucionales (Carlino, 2005). A continuación, se describen, cada uno de estos momentos.

En un primer momento, alrededor de los años setenta y ochenta, la actividad de componer un texto fue estudiada desde la perspectiva cognitiva. Esto permitió analizar la redacción como un proceso en lugar de una serie de etapas, como lo dictaba un paradigma anterior (Flower \& Hayes, 1980). Significa que la escritura no está conformada por trechos interconectados unidireccionales, sino que es el conjunto de todos ellos, y que, además, es un proceso recursivo. Bajo esta perspectiva, el objetivo era dilucidar estrategias para caracterizar a los buenos escritores y así 
aplicarlas en la enseñanza para mejorar los textos (Castelló, 2007). Por lo tanto, es una perspectiva que buscaba hacer una diferenciación entre un escritor novel y uno experto.

En un segundo momento, la investigación abarcó la inclusión del contexto en el análisis del proceso de escritura. Hubo un interés por contestar preguntas de cómo el entorno cultural y social influye en los procesos mentales para el desarrollo de los textos (Flower, 1989). Dicho con otras palabras, y como lo define su autora: una "cognición dentro de su contexto" (Flower, 1989, p. 14). Hasta este momento la visión sobre escribir es extrínseca, debido a que se considera que con el hecho de adquirir recursos lingüísticos una persona se fortalece para afrontar cualquier situación de comunicación. ¡Pero no solo se trata de controlar las elecciones al momento de escribir! Existe un factor intrínseco que se debe considerar porque el trabajo escrito se enmarca dentro del ámbito de cada disciplina para resolver los problemas y las discusiones específicos del campo de estudio (Bazerman, 1988).

Entonces, en un tercer momento, se entiende a la escritura como "una actividad discursiva, dialógica y situada que los miembros de una determinada comunidad desarrollan en un contexto social, cultural e histórico" (Castelló, 2007). Por lo tanto, el análisis del proceso de la escritura toma una dirección diferente en donde ubica al escritor dentro de una comunidad discursiva, que varía según las culturas institucionales (Bazerman, 1988).

La trayectoria de la escritura, al pasar de una visión extrínseca (cognición dentro de su contexto) a una intrínseca (comunidad discursiva), se acompañó a su vez con la aparición de dos movimientos: escribir a través del currículum y escribir en las disciplinas (Carlino, 2005b). El primero, promueve la inserción de la escritura a lo largo de la formación profesional de los estudiantes universitarios y enfatiza su función epistémica (Bazerman et al., 2005). De esta manera, el escritor genera soluciones para resolver un problema de escritura que provoca cambios en su propio conocimiento; y así se cumple la función de escribir para aprender. 
El segundo, pretende ayudar al estudiante para incursionar en las particularidades de la disciplina, lo que requiere un proceso de aprendizaje para dominar el campo del conocimiento y participar de la comunidad discursiva. Por lo tanto, escribir ya no se considera solo como un proceso que se puede delinear en un modelo, sino que requiere un andamiaje docente durante todo el proceso de formación del estudiante. Y así, ayudarlo a formar parte de la comunidad discursiva de su disciplina de estudio.

Un buen proceso de escritura requiere de equipararse con un conjunto de estrategias apropiadas para lograrlo (Cassany, 1989). Y es así como Castelló (2007) orienta que son tres los componentes para determinar cómo se llevará a cabo el proceso de composición: cuánto se domine el tema, qué tanto se conoce a los lectores y la manera en la que se interpreta la tarea que se llevará a cabo. Por esta razón, para lograr textos adecuados a las situaciones de comunicación es indispensable responder ¿cuándo y por qué resultará útil una manera concreta de escribir?

En el primer año de universidad, tanto estudiantes como docentes tienen expectativas que guían la forma de escribir. Una expectativa docente generalizada es que los estudiantes están en la capacidad de analizar de forma adecuada lo que leen, para luego plasmar sus ideas en los textos, independientemente si se les indica cómo hacerlo (Carlino, 2003). Mientras, los alumnos esperan apoyo en el desarrollo de sus competencias académicas, y cuando no lo logran esto se traduce en deserción (Mah \& Ifenthaler, 2018). Esta es una dinámica en la que hay que trabajar para lograr mayor sincronía entre los principales actores del proceso de enseñanza-aprendizaje, es decir, entre los estudiantes y los docentes. 


\section{Materiales y métodos}

El diseño de este estudio es cuantitativo, no experimental y transeccional. La muestra consiste en 183 estudiantes de primer año, que equivale al $87 \%$ de los estudiantes que ingresaron a la universidad en 2020 en la Facultad de Ciencias Químicas y Farmacia, de la Universidad de San Carlos de Guatemala. El cuestionario utilizado es la Encuesta Europea sobre Escritura Académica que es de utilidad para obtener información sobre el proceso de escritura que llevan a cabo los estudiantes en la universidad (Chitez et al., 2015). La dimensión evaluada consta de 13 ítems en escala de Likert. El cuestionario sirve para analizar la importancia que reportan los estudiantes en cuanto a las características del proceso de escritura y al proceso como tal. Las encuestas se realizaron en septiembre de 2020.

Para el análisis de la fiabilidad del instrumento se utiliza el Alfa de Cronbach y el resultado obtenido es de 0.753 . Para la descripción general de las respuestas se analizan medidas de tendencia central (M) y de dispersión (DT).

\section{Resultados y discusión}

El estudio aporta los siguientes resultados con el objetivo de analizar las características del proceso de redacción y la importancia que le dan los estudiantes. Para ello se analizaron dos escalas: características del proceso y el proceso de escritura (Tabla 1). 
Tabla 1. Importancia del proceso de composición según la opinión de los estudiantes.

\begin{tabular}{|c|c|c|}
\hline Ítems & $\mathbf{M}$ & DT \\
\hline \multicolumn{3}{|c|}{ Características del proceso de redacción } \\
\hline Planifico antes de hacer un trabajo escrito. & 3.64 & 0.96 \\
\hline Leo todo antes de empezar a escribir. & 3.83 & 1.01 \\
\hline Mis ideas cambian conforme desarrollo un trabajo. & 3.92 & 0.87 \\
\hline $\begin{array}{l}\text { Reservo una parte considerable de mi tiempo } \\
\text { estimado para hacer una revisión. }\end{array}$ & 3.42 & 1.03 \\
\hline Pido retroalimentación para mejorar mi trabajo. & 3.17 & 1.10 \\
\hline $\begin{array}{l}\text { Mis profesores brindan suficiente retroalimentación } \\
\text { de mis textos/trabajos. }\end{array}$ & 3.07 & 1.00 \\
\hline $\begin{array}{l}\text { Evitar el plagio es un aspecto importante en mi } \\
\text { redacción. }\end{array}$ & 4.50 & 0.83 \\
\hline \multicolumn{3}{|c|}{ b. $\quad$ Proceso de composición } \\
\hline Elaborar un esquema. & 3.13 & 1.05 \\
\hline Hacer una lluvia de ideas. & 3.43 & 1.07 \\
\hline Planificar. & 4.08 & 0.88 \\
\hline Leer. & 4.66 & 0.58 \\
\hline Redactar un borrador. & 3.87 & 0.99 \\
\hline La revisión. & 4.39 & 0.82 \\
\hline
\end{tabular}

$\mathrm{M}=$ media, $\mathrm{DT}=$ desviación. Escala de Likert: $1=\sin$ importancia, $2=$ de poca importancia, $3=$ regular, $4=$ importante y $5=$ muy importante.

Fuente: elaboración propia.

En cuanto a las características de proceso de escritura académica consideran muy importante evitar el plagio (4.50); importante planificar antes de escribir (3.64), leer todo (3.83) y los cambios de ideas conforme redactan un texto 
(3.92). Mientras que consideran de importancia regular a la revisión: prever un tiempo para revisar (3.41), obtener retroalimentación de los profesores (3.07) y de personas externas (3.17).

La manera en la que los estudiantes perciben el proceso de escritura muestra cierta jerarquía dividida en tres grupos: apreciación muy importante, importante y regular (Tabla 1). La primera incluye leer (4.66). La segunda es respecto a planificar (4.01), preparar un borrador (3.87) y revisar el documento (4.39). La última es con relación a elaborar un esquema (3.13) y realizar lluvia de ideas (3.42). Al parecer, tanto esquematizar como tener una lluvia de ideas no forman parte de lo que consideran planificar, y lo más importante es el conocimiento sobre el tema a través de la lectura.

\section{Planificar}

No se cuenta con una fórmula mágica que garantice la redacción de un buen texto. Pero existen estudios que apoyan el hecho de que quienes leen, toman notas y muestran flexibilidad en sus ideas producen textos de mayor calidad (Bazerman et al., 2005; Cassany, 1993). Si bien es cierto que no es una actividad desvinculada de las otras dos (redacción y revisión) o que solo se lleva a cabo al inicio, sí cuenta con tres aspectos básicos para su desarrollo: "generar ideas en cantidad y calidad suficientes, seleccionar y relacionar dichas ideas, y organizarlas de forma esquemática para disponer de una visión general del texto que nos asegure conseguir los objetivos propuestos» (Castelló, 2007, p. 61).

En esta línea, la técnica de lluvia de ideas es una herramienta generadora que puede alimentarse con pensar en la audiencia e imaginar quién leerá el documento. Lo que además permite contestar qué se quiere lograr con el texto y qué tipo de texto se proporcionará (por ejemplo: argumentativo, expositivo, etc.) (Cassany 1993). Después será necesario reflexionar, valorar la adecuación y la pertinencia de dichas ideas para escoger las más apropiadas a la situación de comunicación. 
Finalmente, graficarlas en un esquema permite su mejor organización. En fin, con esta secuencia se puede decir que ya se hace evidente la estructura del texto.

\section{Redactar}

Textualizar es una tarea que varía de acuerdo al género o tipo de texto. La escritura académica es una actividad que requiere de consultar varias fuentes, argumentar, analizar y plasmar las ideas en un texto. Para escribir correctamente resulta de mayor utilidad que el escritor conozca sus fortalezas y debilidades al momento de generar un documento, en lugar de tener una forma específica de llevar a cabo el proceso. En este punto es importante conocer cómo se escribe, de esta manera se logra disminuir el estrés y la ansiedad (Castelló 2007). Esto se logra al detectar en qué momentos se facilita la escritura y cuáles son aquellos en los que parece estar estancada. Por ejemplo, Castelló (2007) sugiere hacer anotaciones en un diario para tomar conciencia de este proceso y así facilitar la comprensión de cómo se redacta.

La escritura colaborativa puede resultar de gran utilidad con los estudiantes de primer ingreso porque les permite conocer cómo escriben otros compañeros. Pero sobre todo porque es común en los ámbitos académicos y es una manera de familiarizarlos con las futuras experiencias de redacción a nivel profesional. Ahora bien, si además se realiza con la ayuda de un especialista que guíe la redacción los resultados son aún mejores (Castelló, 2007). Además, es indispensable hacer ver a los estudiantes que las ideas cambian a lo largo de la redacción, ya sea porque se modifican o porque simplemente se reemplazan. En otras palabras, no es una actividad rígida sino más bien flexible y recursiva (Cassany 1993).

\section{Revisar}

Para entender el significado de la revisión de un texto es útil analizar las estrategias aplicadas por los escritores experimentados en contraposición con los principiantes. 
Los primeros centran su atención en el contenido y toman la revisión como una retroalimentación a su borrador. Los segundos atienden la forma y toman la revisión como una evaluación del documento final (Martínez, 2010). Por lo tanto, es indispensable mostrar a los estudiantes que solo se llega a un texto maduro luego de varios borradores y múltiples revisiones.

Otro aspecto por considerar es que resulta difícil corregir un texto propio ya que no se detectan los errores. Allí entran en juego los compañeros de clase y los docentes, quienes refrescan la percepción del trabajo y tienen un punto de vista más objetivo. Ya que no suplirán la información que hace falta o entenderán las frases confusas y sin coherencia. En la Facultad de Ciencias Químicas y Farmacia una práctica frecuente es revisar y evaluar la versión final que entrega el estudiante, y solicitar que aplique las correcciones al próximo documento que redacte. Así, la revisión es vista como el último paso y no como una parte del proceso de composición. Lo que lleva a que se pierda su potencial recursivo y provoca que los estudiantes le resten importancia a la retroalimentación que reciben.

Al simplificar qué es la revisión se cuenta con la siguiente secuencia: detectar un problema, diagnosticar de forma precisa y proponer una solución. Para detectar y diagnosticar entra en juego la forma en la que se corrige a los alumnos, esta es una oportunidad para ayudarlos a mejorar el texto y no para enfatizar sus errores. Cassany (2006) proporciona una reflexión interesante sobre por qué corregir. Propone a los docentes definir con claridad el objetivo de la corrección antes de llevarla a cabo. Otros autores, como Ávila y colaboradores (2020), presentan cinco aspectos que se deben incluir al momento de corregir: contar con una variedad de focos, con una variedad de modos, permitir promover el aprendizaje, realizar entregas oportunas y tener equilibrio en los juicios (p. 7). En conclusión, no se debe revisar hasta terminar de escribir porque se pierde la recursividad (Castelló, 2007) y promueve la idea de que no es necesario realizar borradores. 
En otro orden de ideas, la jerarquía de la revisión también es importante. La primera etapa debe enfocarse en los aspectos estructurales y de contenido; la segunda en aspectos de cómo están escritas las oraciones, el uso de conectores, etc. y, una tercera, donde se verifican aspectos como la puntuación o la tipografía. Pero, se debe tener cuidado con la revisión porque una "obsesión prematura", que se refiere por corregir la forma antes que el contenido, atenta contra el flujo de ideas y quebranta la creatividad (Cassany, 1993). Más bien debe realizarse de manera recursiva, en donde la estructura inicial se reformula a medida que aparecen nuevas ideas. Por lo tanto, ser flexible para cambiar ideas es un indicio de utilizar la escritura como un proceso y no de forma rígida.

\section{Autorregulación y corregulación}

Por último, otros dos aspectos por tomar en cuenta para escribir son la autorregulación y la corregulación. La autorregulación es un aspecto indispensable que se debe desarrollar para el proceso de redacción. De esta manera, se reconoce que un individuo debe autorregular su escritura no solo con relación al momento de la producción de un texto, sino en función del contexto (Arciniegas, 2016). Aquí es determinante la participación de escritores expertos, ya que juegan un rol indispensable en el desarrollo de actividades o prácticas que conlleven un aprendizaje apropiado de la escritura en las aulas.

Respecto a la corregulación, esta tiene una base sociocultural sobre la producción de textos (Arciniegas, 2016). Quien escribe siempre necesitará mantener un diálogo ya sea con una persona experta en un tema específico, con docentes o con los compañeros de clase. Esto servirá para discutir sobre las ideas, la manera de ordenarlas, cómo presentarlas, etc. Incorporar estas conversaciones ayuda tanto a motivar al estudiante para continuar con el texto, así como para mejorarlo. De esta manera, se considera que implementar el trabajo colaborativo entre expertos, docentes y estudiantes tanto para participar en la evaluación como en la corrección de los textos servirá para desarrollar competencias colaborativas. 
Finalmente, la corregulación es una estrategia que también se aprende. Existe un traspaso de la regulación del experto al aprendiz en proceso de convertirse en escritor. También, y no menos importante, está la corregulación entre pares, ya que el ejercicio de escritura se puede discutir y revisar entre los mismos aprendices. El docente juega el rol de colaborador durante la producción del estudiante, porque en los momentos de revisión funge como experto, y aporta comentarios suficientes y de utilidad. Necesita guiar tanto el progreso del texto como la autorregulación del alumno, hasta que este asuma el control de la producción de su texto (Arciniegas, 2016).

\section{Conclusiones}

Los estudiantes de primer año de la Facultad de Ciencias Químicas y Farmacia consideran que leer todo el contenido y evitar el plagio es lo más importante en el proceso de redacción. Lo que indica que para ellos conocer sobre el tema y citar de forma correcta son características indispensables al momento de escribir.

A pesar de que los estudiantes reportan que la planificación es importante, no parecen dar una importancia igual a las características de generar una lluvia de ideas o usar esquemas para organizarlas. En un futuro será de averiguar qué estrategias consideran como apoyo a la planificación textual.

Para mejorar el proceso de redacción de los estudiantes se debe ayudar a que gestionen estrategias de planificación, textualización y revisión. Estas etapas se atienden a lo largo de todo el desarrollo del texto, pero la primera permite estructurarlo, la segunda requiere conocer el propio estilo y la tercera trata de socializar los avances para mejorarlos. No existe una única ruta para redactar un texto, pero sí hay evidencia de que poner atención a todas las etapas permite obtener mejores resultados que se traducen en textos más elaborados. 


\section{Referencias}

Arciniegas, E. (2016). La escritura socialmente compartida en el aula universitaria: la autorregulación. Lenguaje, 44(2), 197-226. https://doi.org/10.25100/lenguaje.v44i2.4621

Ávila, N., Espinosa, M. J., \& Figueroa, J. (2020). Retroalimentar para enseñar a escribir: 5 principios para una retroalimentación efectiva de la escritura. Prácticas Para Justicia Educacional, 6, 3-9. https://www.researchgate. net/publication/342531020_Retroalimentar_para_ ensenar_a_escribir_5_principios_para_una_ retroalimentacion_efectiva_de_la_escritura

Bazerman, C. (1988). Shaping written knowledge: the genre and the activity of the experimental article in science. The University of Wisconsin Press. https://doi. org/10.2307/357783

Bazerman, C., Little, J., Bethel, L., Chavkin, T., Fouquette, D., \& Garufis, J. (2005). Reference guide to rhetoric and composition: Writing across the curriculum. Parlor Press. https://wac.colostate.edu/books/referenceguides/ bazerman-wac/

Carlino, P. (2003). Leer textos científicos y académicos en la educación superior: obstáculos y bienvenidas a una cultura nueva (1). Uni-Pluri/Versidad, 3(2), 1-9. http:// aprendeenlinea.udea.edu.co/revistas/index.php/unip/ issue/current

Carlino, P. (2005). Los estudios sobre escritura en la universidad:

Reseña para una línea de investigación incipiente.

XII Jornadas de Investigación en Psicología y Primer Encuentro de Investigadores en Psicología del Mercosur "Avances, Nuevos Desarrollos e Integración Regional", Facultad de Psicología de La Universidad de Buenos Aires, 181-185. https://www.aacademica.org/paula.carlino/49

Carlino, P. (2007). Escribir, leer y aprender en la universidad: una introducción a la alfabetización académica. En: P. Carlino (Ed.), Espacios en Blanco. Revista de Educación (Vol. 17). https:// www.aacademica.org/paula.carlino/3.pdf

Cassany, D. (1993). Describir el escribir. Cómo se aprende a escribir (3a.). Ediciones Paidós Ibérica, S.A. https:// vinculacion.unah.edu.hn/dmsdocument/10786-describirel-escribir-daniel-cassany-pdf 
Cassany, D. (2006). Reparar la escritura. Didáctica de la corrección de lo escrito (11 ed.). Editorial Graó. https:// www.academia.edu/37771103/Reparar_la_escritura_Did\%C3\%A1ctica_de_la_correcci\%C3\%B3n_de_lo_ escrito

Castelló, M. (2007). El proceso de composición de textos académicos. En: M. Castelló (Ed.), Escribir y comunicarse en contextos científicos y académicos. Conocimientos y estrategias. (pp. 47-82). Graó. https://es.scribd. com/document/345713367/Castello-2007-El-Proceso-de-Composicion-de-Textos-Academicos

Chitez, M., Kruse, O., \& Castelló, M. (2015). The European Writing Survey ( EUWRIT): background, structure, implementation, and some results. In Working Papers in Linguistics (Vol. 9). Zurich University of Applied Sciences. https://doi.org/10.21256/zhaw-1016

Flower, L. (1989). Studying cognition in context: Introduction to the Study (reading-to-write Report No. 1). Technical Report No. 21. National Center for the Study of Writing, University of California at Berkeley y Carnegie Mellon University. En: L. Flower, V. Stein, J. Ackerman, M. Kantz, K. McCormick, \& W. C. Peck (Eds.), Reading-to-Write: Exploring a Cognitive and Social Process (1990). NY: Oxford University Press. https://doi.org/10.1017/ CB09781107415324.004

Flower, L., \& Hayes, J. R. (1980). The dynamics of composing: making plans and juggling constraints. En: L. Gregg \& E. Steinberg (Eds.), Cognitive processes in writing (pp. 365-387). Lawrence Erlbaum Associates, Inc. https:// books.google.com.gt/books?hl=enflr=gid=a5muDAAAQBAJ\&oi=fnd\&pg=PP1\&dq=Cognitive + processes+in+writing\&ots $=$ sXwJHG5blO\&sig $=$ tI9UjMkcVbB1Wytr_XENnyJmh8g\#v=onepage\& $q=$ Cognitive $\% 20$ processes $\% 20$ in $\% 20$ writing\&f $f=f a l s e$

Mah, D. K., \& Ifenthaler, D. (2018). Students' perceptions toward academic competencies: The case of German first-year students. Issues in Educational Research, 28(1), 120-137. https://www.researchgate.net/ publication/322930511_Students'_perceptions_ toward_academic_competencies_The_case_of_ German_first-year_students 
Marín, J., López, S., \& Roca-de-Larios, J. (2015). El proceso de escritura académica en la universidad española: Percepciones de estudiantes y profesores. Cultura y Educación, 27(3), 504-533. https://doi.org/10.1080/11356 405.2015.1072360

Martínez, J. (2010). La planificación textual y el mejoramiento de la escritura académica. Infancias Imágenes, 9(2004), 3547. http://dialnet.unirioja.es/descarga/articulo/3653126.pdf

Rodríguez, B., \& García, L. (2015). Escritura de textos académicos: dificultades experimentadas por escritores noveles y sugerencias de apoyo. CPU-e, Revista de Investigación Educativa, 20, 249-265. https://doi. org/10.25009/cpue.v0i20.1332

Tovar, F. D., \& Samancá, L. A. (2017). La didáctica en educación superior: Enseñanza orientada al aprendizaje o ciencia aplicada. 72. http://soda.ustadistancia.edu.co/enlinea/congreso/IVcongreso/Articulos/LA\%20DIDACTICA\%20EN\%20 EDUCACION\%20SUPERIOR\%20ENSENANZA.pdf

\section{Semblanza académica de la autora}

La autora está por culminar una Maestría en Docencia Universitaria en la Escuela de Posgrado de la Facultad de Humanidades de la Universidad de San Carlos. Se ha dedicado a la docencia desde 2015 y en la actualidad imparte clases en la Escuela de Biología de la Facultad de Ciencias Químicas y Farmacia de la Universidad de San Carlos de Guatemala. 